\title{
Green Extraction Techniques for Obtaining Bioactive Compounds from Mandarin Peel (Citrus unshiu var. Kuno): Phytochemical Analysis and Process Optimization
}

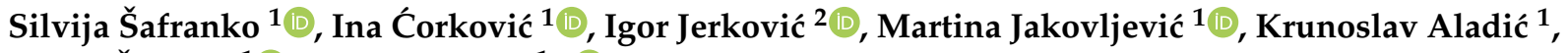 \\ Drago Šubarić ${ }^{1}$ (D) and Stela Jokić ${ }^{1, *(D)}$ \\ 1 Faculty of Food Technology Osijek, University of Osijek, Franje Kuhača 18, 31000 Osijek, Croatia; \\ silvija.safranko@ptfos.hr (S.Š.); ina.corkovic@ptfos.hr (I.Ć.); mjakovljevic@ptfos.hr (M.J.); \\ kaladic@ptfos.hr (K.A.); dsubaric@ptfos.hr (D.Š.) \\ 2 Faculty of Chemistry and Technology, University of Split, Ruđera Boškovića 35, 21000 Split, Croatia; \\ igor@ktf-split.hr \\ * Correspondence: sjokic@ptfos.hr; Tel.: +385-31-224-333
}

Citation: Šafranko, S.; Corković, I.; Jerković, I.; Jakovljević, M.; Aladić, K.; Šubarić, D.; Jokić, S. Green Extraction Techniques for Obtaining Bioactive Compounds from Mandarin Peel

(Citrus unshiu var. Kuno)

Phytochemical Analysis and Process Optimization. Foods 2021, 10, 1043. https://doi.org/10.3390/ foods 10051043

Academic Editor: Christopher John Smith

Received: 1 April 2021

Accepted: 8 May 2021

Published: 11 May 2021

Publisher's Note: MDPI stays neutral with regard to jurisdictional claims in published maps and institutional affiliations.

Copyright: (c) 2021 by the authors. Licensee MDPI, Basel, Switzerland. This article is an open access article distributed under the terms and conditions of the Creative Commons Attribution (CC BY) license (https:/ / creativecommons.org/licenses/by/ $4.0 /)$.

\begin{abstract}
In this study, an efficient utilization and valorization of mandarin peel (Citrus unshiu Marc. var. Kuno) was investigated using innovative and green extraction techniques. The first step of this study included the extraction and analysis of the volatile compounds by performing a supercritical $\mathrm{CO}_{2}\left(\mathrm{SC}-\mathrm{CO}_{2}\right)$ extraction under different operating pressure conditions (100 and $300 \mathrm{bar}$ ). The analysis of volatile compounds of the obtained extracts was conducted by gas chromatography-mass spectrometry (GC-MS), and limonene was found to be the dominant volatile component (13.16\% at 100 bar; $30.65 \%$ at 300 bar). After SC- $\mathrm{CO}_{2}$ treatment, the exhausted citrus peel waste enriched with bioactive compounds was subjected to subcritical water extraction (SWE) in a wide temperature range $\left(130-220^{\circ} \mathrm{C}\right)$ using different solvent-solid ratio $(10-30 \mathrm{~mL} / \mathrm{g})$ in time periods from 5 to $15 \mathrm{~min}$, in order to obtain bioflavonoids. Identification and quantification of present bioflavonoids was conducted by high-performance liquid chromatography with a with a diode array detector (HPLC), and hesperidin (0.16-15.07 $\mathrm{mg} / \mathrm{g}$ ) was determined as the most abundant flavanon in mandarin peel with other polyphenolic compounds that were possible by-products of thermal degradation. At higher temperatures, the presence of 5-hydroxymethylfurfural (5-HMF) and chlorogenic acid were detected. Antiradical activity and total phenolic content in the extracts were determined using spectrophotometric methods, while the process optimization was performed by response surface methodology (RSM).
\end{abstract}

Keywords: mandarin peel; green extraction; bioactive compounds; bioflavonoids; volatilecompounds

\section{Introduction}

The main goal of the industry is to develop and ensure high-quality products followed by the efficient utilization of raw material, minimizing food loss and management costs, reducing also industry waste. The major concern of food-processing industry is efficient waste management and adequate waste disposal [1]. Citrus fruits, which belong to the Rutaceae family, play an important role in food-processing industry and agro-industrial sector, and they were considered as one of the most commonly cultivated and consumed fruits all over the world [2,3]. The main industrial product of citrus processing is undoubtely juice, including also other products such as jams, marmelades, flavouring agents, candied peel and essential oils [4-6].

In general, the industrial processing of citrus fruits generates large amounts of organic waste, mainly composed of the peel, pulp, membrane and seed residue [3,7]. Because of the negative environmental impact, it is essential to develop the novel strategies toward the reduction and adequate waste disposal [8-10]. Therefore, the novel scientific studies are 
focused on the valorization of citrus residue with the primary objective of developing of innovative products enriched with bioactive compounds with the emphasis on the efficient waste utilization [5,11-13]. Citrus peels contain high contents of vitamin C, fibers, pectins, essential oils and polyphenols (phenolic acids and flavonoids), having strong potential to be exploited as a value-added products, especially for the purposes of food industry, biotechnology and pharmaceutical industry [13-15]. Essential oils (EOs) are considered as plant-based natural products comprised of volatile and aromatic compounds widely used in pharmaceuticals, while important commercial application of EOs has been achieved as natural preservatives in food industry [16]. The aromatic profile of citrus peel consists of monoterpenes (e.g., limonene) in majority, following by sesquiterpene hydrocarbons, and their oxygenated derivatives (ketones, aldehydes, alcohols and esters). Limonene is predominant monoterpene in citrus peel, while in lower concentrations linalool, octanal, citronellal can be detected in natural citrus peel essential oils [5,17]. It is well-known that citrus peels are rich in phenolic components, among which flavonoids are most commonly studied due to their beneficial effects to human health $[14,15,17]$. The most abundant bioflavonoids present in citrus fruits are flavanones, with the predominance of hesperidin with beneficial biological activity exhibiting antioxidant [18], anti-inflammatory [18,19], neuroprotective [20], and antitumor effects [21]. Other important and beneficial flavonoids are narirutin, rutin, diosmin, didymin, sinensetin, and tangeretin which could be detected in small quantites or are available in traces in citrus extracts [22].

In order to obtain the extracts rich in oils, fatty acids or in flavonoids, it is essential to select the appropriate extraction method, primarily solvent and optimize process regarding operating conditions to extract target compounds. Green and sustainable extraction techniques are environmentally-friendly, safe, non-toxic and promising alternatives to the conventional extraction methods. Supercritical $\mathrm{CO}_{2}$ extraction $\left(\mathrm{SC}-\mathrm{CO}_{2}\right)$ method enables the extraction of volatile and nonpolar compounds due to the nonpolar characteristics of $\mathrm{CO}_{2}$ molecules. However, the water in subcritical state (SWE) could obtain extracts rich in flavonoids and phenolic compounds in general, due to the physicochemical changes of solvent under subcritical conditions [5,22]. It is noteworthy to emphasize that there are only few studies reporting SWE methods from citrus peel [5,22-25], however combination of SC-CO $\mathrm{CO}_{2}$ and SWE extraction with aromatic profile and phenolic compounds characterization and identification from mandarin peel has not yet been reported.

This study is divided into two phases: (a) the first part of experiments was related to SC- $\mathrm{CO}_{2}$ extraction of mandarin peel (Citrus unshiu Marc. var. Kuno) and analysis of volatile compounds by gas chromatography-mass spectrometry (GC-MS); (b) in the second part of experiment the exhausted material remained after $\mathrm{SC}-\mathrm{CO}_{2}$ method was further used for obtaining phenolic compounds by SWE. The primary hypothesis was that different applied pressures during $\mathrm{SC}-\mathrm{CO}_{2}$ extraction could obtain aromatic and volatile components of different chemical complexities and the most significant differences in chemical composition of extracts were noticeable at wider ranges of the operating pressures. By removing nonpolar components by SC- $\mathrm{CO}_{2}$ extraction, the exhausted material enriched with polyphenolic compounds remained and was extracted by SWE. Qualitative and quantitative analysis of flavonoids was carried out by a high-performance liquid chromatography with a diode array detector (HPLC). The influence of different operating parameters which have the most significant influence during SWE process (temperature, time, and solvent-solid ratio) was investigated, while optimal conditions toward maximizing content of individual flavonoids (desirable components) in the extracts and at the same time minimizing the content of 5-hydroxymethylfurfural (5-HMF) (undesirable component) were also determined. Antiradical activity and total phenolic content in the extracts were determined using standard spectrophotometric methods. This study could be an excellent example of waste valorization by combining two innovative extraction techniques from mandarin peel with the purpose to obtain extracts rich in aromatic as well as extracts rich in phenolic components, respectively. 


\section{Materials and Methods}

\subsection{Chemicals and Plant Material}

The mandarin peels (Citrus unshiu Marc.) of the variety "Kuno" were obtained in November 2019 from a small family farm Dalibor Ujević (Opuzen, Croatia). Before the extraction, the mandarin peels were washed several times in distilled water, freeze-dried (Alpha LSCplus, Christ, Germany) and milled using a IKA M 20 universal laboratory mill (IKA-Werke GmbH, Staufen, Germany). Carbon dioxide $\left(\mathrm{CO}_{2}\right)$ used in $\mathrm{SC}-\mathrm{CO}_{2}$ extraction was $99.97 \%(w / w)$ pure (Messer, Osijek, Croatia). The HPLC standard hesperidin (purity 89.5\%) was obtained from Dr. Ehrenstorfer GmBH (Augsburg, Germany), while narirutin (purity $\geq 98 \%$ ), naringin (purity $\geq 95 \%$ ), and chlorogenic acid (purity $\geq 98 \%$ ) were purchased from Sigma-Aldrich (Steiheim, Germany). Standards 5-HMF (purity 98\%) and rutin (purity 97\%) were purchased from Acros Organics (Geel, Belgium). Chemicals 2,2-diphenyl-1-picrylhydrazyl (DPPH) and Folin-Ciocalteu's phenol reagent were purchased from Sigma-Aldrich Chemie (Steiheim, Germany). All other solvents were of analytical grade (J.T. Baker, Phillipsburg, NJ, USA). Milli-Q pure water was used during experiments and analytical measurements obtained by Milli-Q Millipore system (conductivity $\leq 0.054 \mu \mathrm{S} / \mathrm{cm}$ ).

\subsection{Supercritical $\mathrm{CO}_{2}\left(\mathrm{SC}-\mathrm{CO}_{2}\right)$ Extraction}

In order to obtain the extracts rich in aromatic and volatile compounds, supercritical $\mathrm{CO}_{2}\left(\mathrm{SC}-\mathrm{CO}_{2}\right)$ extractions were performed in SFE system previously described in details [5,26]. For each experiment, overall $100.0 \mathrm{~g}$ of freeze-dried mandarin peel was used, milled in a laboratory mill, and then placed into the extractor vessel made of a stainless steel bar (AISI 304), with the outer diameter (OD) of $100 \mathrm{~mm}$ and a height of $500 \mathrm{~mm}$. The extraction experiments were carried out under different pressure conditions (100 and 300 bar), at constant temperature of $40^{\circ} \mathrm{C}$ and $\mathrm{CO}_{2}$ mass flow rate of $2 \mathrm{~kg} / \mathrm{h}$ controlled through Matheson FM-1050 (E800) flowmeter (Matheson Tri-Gas, Inc., Basking Ridge, NJ, USA). The extractions were carried out for $90 \mathrm{~min}$, and total extract was collected directly in the glass tube, previously weighted to establish the exact amount of extracts. The obtained extracts were subjected to further GC-MS analysis., and the exhausted material after $\mathrm{SC}-\mathrm{CO}_{2}$ extraction were kept at $4-6{ }^{\circ} \mathrm{C}$ until performing SWE experiments.

\subsection{GC-MS Analysis}

Gas chromatography and mass spectrometry (GC-MS) analyses were performed on a gas chromatograph model 7890A (Agilent Technologies, Palo Alto, CA, USA) with 5975C mass detector (Agilent Technologies, Palo Alto, CA, USA). The operating conditions were: capillary column HP-5MS (5\%-phenyl-methyl polysiloxane, $30 \mathrm{~m} \times 0.25 \mathrm{~mm}$ i.d., coating thickness $0.25 \mu \mathrm{m}$ ); carrier gas Helium: $1 \mathrm{~mL} / \mathrm{min}$; injector temperature: $250{ }^{\circ} \mathrm{C}$; HP-5MS column was heated at $70{ }^{\circ} \mathrm{C}$ isothermal for $2 \mathrm{~min}$, and then the temperature was increased to $200{ }^{\circ} \mathrm{C}$ at a rate of $3{ }^{\circ} \mathrm{C} / \mathrm{min}$ and then held isothermal for $18 \mathrm{~min}$; the split ratio: 1:50; ionization voltage: $70 \mathrm{eV}$; ion source temperature: $230{ }^{\circ} \mathrm{C}$; mass scan range: 45-450 mass units [27]. The extracts obtained by SC- $\mathrm{CO}_{2}(10 \mathrm{mg})$ were diluted with hexane and $1 \mu \mathrm{L}$ of the solution was inserted into the GC injector. The compounds identification was performed by the comparison of their retention indices (RI), determined relative to the retention times of $n$-alkanes $\left(\mathrm{C}_{9}-\mathrm{C}_{25}\right)$, with those reported in the literature (National Institute of Standards and Technology) and their mass spectra with the Wiley 9 (Wiley, New York, NY, USA) and NIST 17 (D-Gaithersburg) mass spectral libraries. The compounds percentage composition was calculated from the GC peak areas using the normalization method without correction factors. The component percentages were calculated as mean values from duplicate GC-MS analyses of all extracts.

\subsection{Subcritical Water Extraction (SWE) Technique}

The exhausted material remained after $\mathrm{SC}-\mathrm{CO}_{2}$ procedure at operating pressure of 300 bar was further used as raw material for the extraction of phenolic compounds using subcritical water extraction (SWE) technique after previously removing aromatic and 
nonpolar components by SC-CO $\mathrm{CO}_{2}$ procedure. SWE extraction experiments were carried out in a handmade SWE system previously described by Jokić et al. [28]. The extraction vessel made from stainless steel bar (AISI 304) was filled with $1.0 \mathrm{~g}$ of pretreated plant material of mandarin peel, and nitrogen was injected to prevent oxidation processes during thermal exposure and by the presence of oxygen from air. The experiments were performed by varying operating conditions which are investigated to have possible influence on SWE process: temperature $\left(130-220^{\circ} \mathrm{C}\right)$, time (5-15 min), and solvent-solid ratio $(10-30 \mathrm{~mL} / \mathrm{g})$. The final product was filtered containing water-soluble phase (extract) and solid residue. The obtained aqueous extracts were further analyzed for phenolic compounds using HPLC technique.

\subsection{HPLC Analysis}

Determination of 5-HMF, bioflavonoids and chlorogenic acid was performed by HPLC (high performance liquid chromatography) method with UV detection, on Cosmosil 5C18MS-II column (Nacalai Tesque, Inc., Kyoto, Japan), $250 \mathrm{~mm}$ long with an internal diameter of $4.6 \mathrm{~mm}$, filled with $5 \mu \mathrm{m}$ particles. The analysis was performed on a semi-preparative HPLC device (Agilent, 1260 Infinity II series). The HPLC system used for the analysis consisted of a quaternary pump (G7111A), a column chamber (G7116A), a photo-diode array detector (G7115A), an autosampler (G7157A), and a fraction collector (G1364E). The system was operated using a computer program Prep LC Online. The separation of analyzed compounds was performed by gradient elution for $50 \mathrm{~min}$, where $1 \% \mathrm{CH}_{3} \mathrm{COOH}$ (in Milli-Q water) was used as the phase A and methanol as the phase B, with 80:20

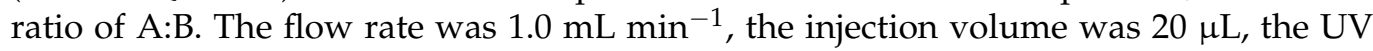
detection wavelengths were 283 and $360 \mathrm{~nm}$, and the analysis was performed at $25^{\circ} \mathrm{C}$. The gradient conditions were: $0-5 \mathrm{~min} 80 \%$ of A, 5-15 $\mathrm{min} 80-40 \%$ of A, 15-35 min holding $20 \%$ of A, 35-40 $\min 20-40 \%$ of A, $40-50 \mathrm{~min} 40-80 \%$ of A. The standard stock solution for hesperidin was prepared in dimethyl sulfoxide (DMSO) and diluted with methanol, and for other components the standard solutions were prepared in methanol. The compounds 5-HMF, hesperidin, narirutin and chlorogenic acid were detected at $283 \mathrm{~nm}$, while rutin was detected at $360 \mathrm{~nm}$. The calibration for 5-HMF was obtained at seven concentrations (10-1000 mg/L), for hesperidin at seven concentrations (1.0-1500 mg/L), for narirutin at six concentrations (10-150 mg/L), for rutin at seven concentrations (10-500 mg/L) and for chlorogenic acid at eight concentrations (10-1000 mg/L). The linearity of the calibration curve was confirmed by $\mathrm{R}^{2}=0.99927$ for $5-\mathrm{HMF}, \mathrm{R}^{2}=0.99920$ for hesperidin, $\mathrm{R}^{2}=0.99888$ for narirutin, $\mathrm{R}^{2}=0.99842$ for rutin and $\mathrm{R}^{2}=0.99912$ for chlorogenic acid. The retention time for 5-HMF was $5.221 \mathrm{~min}$, for chlorogenic acid $12.333 \mathrm{~min}$, for narirutin $18.368 \mathrm{~nm}$, for hesperidin $18.838 \mathrm{~min}$ and for rutin $19.034 \mathrm{~min}$.

The sample analysis was performed in duplicate, and two injections were performed from each prepared solution. The compounds content in the analyzed samples were expressed in $\mathrm{mg} / \mathrm{g}$ of peels (further in the text expressed as $\mathrm{mg} / \mathrm{g}$ ).

\subsection{Determination of Antiradical Activity}

Determination of antiradical activity of SWE extracts of mandarin peel was performed by standard DPPH spectrophotometric method [29]. A volume of $0.5 \mathrm{~mL}$ of freshly prepared DPPH methanolic solution $(0.3 \mathrm{mM})$ was added to the $1.2 \mathrm{~mL}$ of the extract $(1.0 \mathrm{mg} / \mathrm{mL})$. The reaction mixtures were kept in dark for $30 \mathrm{~min}$ before the measurements. The absorbances were measured at $517 \mathrm{~nm}$ (Spectronic Helios Gamma UV-Vis spectrophotometer; Thermo Fisher Scientific, Waltham, MA, USA), and all experiments were performed in three replicates, while the results are expressed as mean percentage inhibition \pm standard deviations.

\subsection{Determination of Total Phenolic Content}

The content of total phenols of SWE extracts of mandarin peel was determined by spectrophotometric method using Folin-Ciocalteu reagent. Briefly, in $200 \mu \mathrm{L}$ of SWE 
extracts $(10.0 \mathrm{mg} / \mathrm{mL})$ was added $100 \mu \mathrm{L}$ of Folin-Ciocalteu reagent, $300 \mu \mathrm{L}$ of $20 \% \mathrm{Na}_{2} \mathrm{CO}_{3}$ aqueous solution, and then Milli-Q water (conductivity $\leq 0.055 \mu \mathrm{S} / \mathrm{cm}$ ) was added to the mixture to the overall volume of $2 \mathrm{~mL}$ of the mixture. Methanol was used as a blank sample. Finally, the reaction mixtures were incubated at $40{ }^{\circ} \mathrm{C}$ for $30 \mathrm{~min}$. For the preparation of calibration curve, gallic acid was used as standard compound. The absorbances were measured at $765 \mathrm{~nm}$ using a Shimadzu UV-1280 spectrophotometer (Shimadzu, Kyoto, Japan). The obtained results were expressed as $\mathrm{mg}$ of gallic acid equivalent per $\mathrm{g}$ of peel material (mg GAE/g). All experiments were carried out in triplicate and the results are expressed as mean values \pm standard deviations.

\subsection{Experimental Design and Process Optimization}

Experimental data generated by Box-Behnken design (BBD) [30] and response surface methodology (RSM) were used to derive optimal process parameters and to evaluate model adequacy for each individual response $(y)$ obtained by SWE extraction of the citrus waste material pretreated by $\mathrm{SC}-\mathrm{CO}_{2}$ procedure. The extraction parameters such as temperature $\left(X_{1}\right)$, time extraction $\left(X_{2}\right)$ and solvent-solid ratio $\left(X_{3}\right)$ are independent variables investigated for the influence of individual variable on the SWE process (Table 1), more precisely on the dependent variable or response $(y)$. Obtained data were fitted with a second order (quadratic) response models described by the following Equation (1):

$$
y=\beta_{0}+\sum_{i=1}^{k} \beta_{i} X_{i}+\sum_{i=1}^{k} \beta_{i i} X_{i}^{2}+\sum_{\substack{i=1 \\ i<j}}^{k-1} \sum_{j=2}^{k} \beta_{i j} X_{i} X_{j}
$$

where $y$ represents set of investigated responses (target bioactive compounds in SWE extracts), $\beta_{0}, \beta_{i}, \beta_{i i}, \beta_{i j}$ parameters are designated as constant coefficients of intercept, linear, quadratic, and interaction terms, respectively; $X_{i}$ and $X_{j}$ are coded $(-1,0,+1)$ inputs or independent variables. The response of chlorogenic acid was fitted to the reduced cubic model without transformation. The process optimization was performed for the three identified and most abundant phenolic components (hesperidin, narirutin, and rutin) and possible degradation products chlorogenic acid and 5-HMF detected in SWE extracts, while evaluation of the developed models was done by performing experiments according to the calculated optimal operating conditions. The statistical analysis was carried out using commercial software Design-Expert $^{\circledR}$ (ver. 9, Stat-Ease Inc., Minneapolis, MN, USA). The quality of fitted mathematical models was evaluated by the analysis of variance (ANOVA).

Table 1. The uncoded and coded levels of independent variables used in the RSM design for SWE technique from citrus material pretreated by $\mathrm{SC}-\mathrm{CO}_{2}$ extraction.

\begin{tabular}{ccccc}
\hline \multirow{2}{*}{ Independent Variable } & Symbol & \multicolumn{3}{c}{ Level } \\
\cline { 3 - 5 } & & Low (-1) & Center (0) & High (+1) \\
\hline Temperature $\left({ }^{\circ} \mathrm{C}\right)$ & $X_{1}$ & 130 & 175 & 220 \\
Extraction time $(\mathrm{min})$ & $X_{2}$ & 5 & 10 & 15 \\
Solvent-solid ratio $(\mathrm{mL} / \mathrm{g})$ & $X_{3}$ & 10 & 20 & 30 \\
\hline
\end{tabular}

\section{Results and Discussion}

By combining two innovative extraction techniques, $\mathrm{SC}-\mathrm{CO}_{2}$ and $\mathrm{SWE}$, total reusage of the citrus waste material could be achieved in order to obtain the valuable compounds. By applying different operating pressures in $\mathrm{SC}-\mathrm{CO}_{2}$ extraction procedure, nonpolar compounds of different complexities could be obtained [5]. The increase in the extraction pressure causes the increase in the $\mathrm{SC}-\mathrm{CO}_{2}$ density and solvent solubility, enhancing its extracting power and process yield [31]. Hence, in order to compare the efficiency of the extraction on the yield and the composition of volatile components by SC-CO method, the variations in two operating pressures (100 and 300 bar) were employed. It is well- 
known that volatile and low-molecular-weight compounds could be extracted under lower applied pressure (essential oils), while with the increase of pressure in the system less volatile and higher molecular weight could be obtained (fatty acids, waxes, etc.) [32]. Two pressures in wide range $\left(100,300\right.$ bar) were used in the $\mathrm{SC}-\mathrm{CO}_{2}$ extraction process, while temperature and $\mathrm{CO}_{2}$ flow rate were kept constant due to the many years of author's experience in the field of $\mathrm{SC}-\mathrm{CO}_{2}$ extraction and the fact that temperature and pressure have no significant effect on the final product. The applied temperature of $40{ }^{\circ} \mathrm{C}$ is a temperature where $\mathrm{CO}_{2}$ is in supercritical state, but the temperature is low enough to prevent degradation of thermolabile compounds, preventing also damage of their structure. By removing aromatic and volatile compounds from the citrus material, the extractability of the remained bioflavonoids could be enhanced by using SWE. It has been also reported that at the temperature of $150{ }^{\circ} \mathrm{C}$, dielectric constant $(\varepsilon)$ of water decreases and chemical characteristics of solvent is equal to those of DMSO at $25^{\circ} \mathrm{C}$, which means that compounds of different polarity could be obtained by varying operating conditions of SWE [22]. The first observations in this study were made according to the physical appearance of the extracts obtained by SWE. The color of the obtained extracts changed from characteristic orange color to brown color depending on the applied temperature. This color derived from both components found in the citrus peel as well as from by-products of Maillard reactions. The color appeared more intense and dark brown with the increase in the extraction temperature, while Cvetanović et al. [33] reported that the rate of this reaction increases significantly between $140^{\circ} \mathrm{C}$ and $160^{\circ} \mathrm{C}$.

\subsection{GC-MS Analysis of SC-CO $\mathrm{CO}_{2}$ Extracts}

The most abundant aromatic compound, as expected was monoterpene hydrocarbon limonene $(13.16 \% ; 30.65 \%)$, being more abundant at 300 bar. It was previously noted that the percentages of limonene, as the major typical volatile compound of Citrus peels, in general was lower than in pressed Citrus peel oils [27], but $\mathrm{SC}-\mathrm{CO}_{2}$ extraction provided enriched profiles of volatiles and semi-volatiles with respect to oxygenated monoterepenes and sesquiterpenes. Lopresto et al. [34] performed the extractions on the lemon peel in order to obtain the extracts rich in volatile compounds. They reported that hydrodistillation gave the isolate enriched in monoterpene limonene, with superior performance compared to $\mathrm{SC}-\mathrm{CO}_{2}$ extraction. The authors emphasized that the possible reason of the lower recovery of limonene $(17.97 \% ; 35.71 \%)$ obtained by SC- $\mathrm{CO}_{2}$ extraction is due to the lower selectivity of $\mathrm{SC}-\mathrm{CO}_{2}$ toward monoterpenes. With the increase of operating pressure from 100 to 300 bar, the solvent power has enhanced, extraction selectivity is lower, and significant content of waxes could be extracted causing the decrease in content of essential oils in SC- $\mathrm{CO}_{2}$ extract. Another more abundant monoterpenes (Table 2) were: $\gamma$-terpinene, linalool and $\alpha$-terpineol. On the other hand, among sesquiterpene hydrocarbons, the most abundant were $\alpha$-farnesene $(10.63 \% ; 5.72 \%)$, germacrene D $(6.66 \% ; 4.11 \%)$, eremophilene $(6.7 \% ; 3.99 \%)$, followed by $\gamma$-cadinene, germacrene B and others (Table 2$)$. Another group of highly abundant compounds were fatty acids, particularly linoleic acid and hexadecanoic acid (Table 2). However, those acids are not typical flavor compounds of the citrus peels. The obtained results are partially similar to the $\mathrm{SC}-\mathrm{CO}_{2}$ extraction at $40{ }^{\circ} \mathrm{C}$ and $10 \mathrm{MPa}$ at $1.76 \mathrm{~kg} / \mathrm{h}$ of the peels of Citrus aurantium L. and Citrus sinensis Osbeck cultivars from the Dubrovnik region (south Croatia) with relevant similarities among the peel oil compositions of C. aurantium and C. sinensis cultivars with limonene predominance (up to 54.3\%) [33]. The principal present oxygenated monoterpenes were linalool (3.0-5.9\%), $\alpha$-terpineol $(0.7-2.4 \%)$, linalyl acetate $(0.0-5.0 \%)$, geranyl acetate $(0.0-0.4 \%),(Z)$-citral $(0.0-1.8 \%)$ and (E)-citral (0.0-1.9\%), while several sesquiterpenes were found with minor percentages. However, coumarin derivatives (isogeijerin, scoparone, bergapten, or osthole, 7-methoxy-8(2-formylpropyl)coumarin) found among relevant compounds in mentioned research were not identified in the present research. 
Table 2. The volatiles profile of SC-CO $\mathrm{CO}_{2}$ extracts * of mandarin peel var. Kuno determined by GC-MS analysis.

\begin{tabular}{|c|c|c|c|c|c|c|c|}
\hline No. & Compound & 100 Bar (\%) & 300 Bar (\%) & No. & Compound & 100 Bar (\%) & 300 Bar (\%) \\
\hline 1. & $\alpha$-Pinene & 0.03 & 0.09 & 27. & Undecanal & 0.09 & 0.06 \\
\hline 2. & Sabinene & - & 0.04 & 28. & $\delta$-Elemene & 0.31 & 0.4 \\
\hline 3. & Hexanoic acid & 0.05 & 0.03 & 29. & $\alpha$-Cubebene & 0.11 & 0.08 \\
\hline 4. & $\beta$-Myrcene & 0.13 & 0.54 & 30. & Citronellyl acetate & 0.24 & 0.15 \\
\hline 5. & $\alpha$-Terpinene & - & 0.04 & 31. & Neryl acetate & 0.43 & 0.28 \\
\hline 6. & p-Cymene & 0.04 & - & 32. & $\alpha$-Copaene & 1.46 & 0.89 \\
\hline 7. & Limonene & 13.16 & 30.65 & 33. & Geranyl acetate & 0.72 & 0.45 \\
\hline 8. & (Z)- $\beta$-ocymene & 0.02 & 0.05 & 34. & $\beta$-Elemene & 0.99 & 0.86 \\
\hline 9. & $\gamma$-Terpinene & 1.75 & 3.69 & 35. & Dodecanal & 0.23 & 0.13 \\
\hline 10. & cis-Sabinene hydrate & 0.11 & 0.16 & 36. & trans-Caryophyllene & 0.9 & 0.54 \\
\hline 11. & $\alpha$-Terpinolene & 0.17 & 0.32 & 37. & Valencene & 0.51 & 0.3 \\
\hline 12. & Linalool & 2.18 & 1.58 & 38. & $\alpha$-Muurolene & 0.63 & - \\
\hline 13. & Nonanal & 0.07 & 0.06 & 39. & Eremophilene & 6.7 & 3.99 \\
\hline 14. & trans- $p$-mentha-2,8-dien-1-ol & - & 0.02 & 40. & $\gamma$-Cadinene & 2.21 & 1.38 \\
\hline 15. & trans-Limonene oxide & 0.02 & 0.02 & 41. & Germacrene B & 1.11 & 0.69 \\
\hline 16. & Citronellal & 0.11 & 0.1 & 42. & Dodecanoic acid & 0.34 & 0.32 \\
\hline 17. & Terpinen-4-ol & 0.22 & 0.16 & 43. & $t$-Muurulol & 0.07 & 0.06 \\
\hline 18. & Octanoic acid & 0.08 & 0.05 & 44. & 3-Oxo- $\alpha$-ionol & - & - \\
\hline 19. & $\alpha$-Terpineol & 2.1 & 1.31 & 45. & $\alpha$-Sinensal & 0.08 & 0.05 \\
\hline 20. & Decanal & 0.53 & 0.37 & 46. & Tetradecanoic acid & 2.42 & 1.56 \\
\hline 21. & $\beta$-Citronelol & 0.19 & 0.13 & 47. & Nootkatone & 0.14 & 0.13 \\
\hline 22. & Perilla aldehyde & 0.43 & 0.3 & 48. & Octadecan-1-ol & 0.18 & 0.17 \\
\hline 23. & Nonanoic acid & 0.08 & 0.06 & 49. & Heptadecanoic acid & 0.19 & 0.4 \\
\hline 24. & $p$-Mentha-1,8-dien-9-ol & 0.23 & 0.15 & 50. & Linoleic acid & 15.44 & 19.04 \\
\hline 25. & Thymol & 0.09 & 0.08 & 51. & Oleic acid & 2.87 & - \\
\hline 26. & Carvacrol & 0.19 & 0.12 & & & & \\
\hline
\end{tabular}

\subsection{Identification and Quantification of the Compounds in SWE Extracts Using HPLC}

The mandarin peel residue after $\mathrm{SC}-\mathrm{CO}_{2}$ extraction was used for further extraction of more polar components with subcritical water and their content was determined by HPLC. The residue obtained by SC- $\mathrm{CO}_{2}$ extraction performed at 300 bar was selected for further investigation of polyphenolic compounds as higher recovery of limonene and content of fatty acids was observed. Overall of 17 extractions were performed according to the BBD experimental design using SWE. The results have indicated that the significant concentrations of the compounds 5-HMF, hesperidin, narirutin, rutin, and chlorogenic acid were detected in the obtained extracts. The results of individual components are expressed as $\mathrm{mg} / \mathrm{g}$ of the peels (exhausted material) after $\mathrm{CO}_{2}$ extraction and are shown in Table 3.

It is well known fact that the composition of the extract, as well as the amount of individual components, depended also on the extraction conditions as can be seen in Table 3. Given the noticeable differences in the number and quantity of components, the chromatographic profile of extracts, obtained under the following conditions of $220^{\circ} \mathrm{C}$, time of $10 \mathrm{~min}$, using $30 \mathrm{~mL} / \mathrm{g}$ ratio (sample 17), and the extract obtained at $130^{\circ} \mathrm{C}, 15 \mathrm{~min}$, and $20 \mathrm{~mL} / \mathrm{g}$ are selected and presented in Figure S1 (sample 8). As can be seen from Figure S1, five major and several minor peaks were observed at $283 \mathrm{~nm}$, of which five were identified. The largest peak was identified as 5-HMF (Figure S1b, peak 1). The second peak was identified as chlorogenic acid, the third peak was hesperidin, while the fourth was naringenin. Peak identification was performed by comparing retention times and UV spectra with commercial standards (Figure S2). In addition to the appearance of the UV spectrum, the correspondence between the spectra of the standards of unknown peaks is shown, with a coincidence of $82.21 \%$ to $98.00 \%$ depending on the component (Figure S2). In this way, comparing the retention times and UV spectra the identity of the components was confirmed, while the concentrations of detected components were calculated by reference 
to the external standard curve constructed using various concentrations of each of the commercially available standard compounds.

Table 3. Experimental design for SWE procedure and obtained contents of polyphenolic compounds analyzed by HPLC.

\begin{tabular}{|c|c|c|c|c|c|c|c|c|}
\hline \multicolumn{4}{|c|}{ Experimental Design (BBD) } & \multicolumn{5}{|c|}{ Compound (mg/g of Peels) } \\
\hline Run & Temperature $\left({ }^{\circ} \mathrm{C}\right)$ & Time (min) & Solvent-Solid Ratio (mL/g) & 5-HMF & Hesperidin & Narirutin & Rutin & Chlorogenic Acid \\
\hline 1. & 175 & 10 & 20 & 4.68 & 9.28 & 3.65 & 3.14 & 0.27 \\
\hline 2. & 175 & 15 & 10 & 4.32 & 8.56 & 1.05 & 0.89 & 1.90 \\
\hline 3. & 130 & 10 & 30 & 0.01 & 9.19 & 3.83 & 1.31 & 0.28 \\
\hline 4. & 220 & 5 & 20 & 10.08 & 0.19 & 0.09 & 0.19 & 58.93 \\
\hline 5. & 175 & 15 & 30 & 9.48 & 14.89 & 4.27 & 3.91 & 8.69 \\
\hline 6. & 175 & 10 & 20 & 6.48 & 10.52 & 3.63 & 3.03 & 3.62 \\
\hline 7. & 220 & 10 & 10 & 5.38 & 1.15 & 0.03 & 0.80 & 21.26 \\
\hline 8. & 130 & 15 & 20 & 0.00 & 11.25 & 4.87 & 1.04 & 0.00 \\
\hline 9. & 130 & 10 & 10 & 0.00 & 3.66 & 1.99 & 0.52 & 0.08 \\
\hline 10. & 175 & 5 & 30 & 7.83 & 15.07 & 4.72 & 4.21 & 0.28 \\
\hline 11. & 175 & 5 & 10 & 3.67 & 5.28 & 1.91 & 1.68 & 0.79 \\
\hline 12. & 175 & 10 & 20 & 6.18 & 9.61 & 3.44 & 2.94 & 1.98 \\
\hline 13. & 175 & 10 & 20 & 6.02 & 11.23 & 3.38 & 2.81 & 1.84 \\
\hline 14. & 220 & 15 & 20 & 6.39 & 0.16 & 0.08 & 0.18 & 54.48 \\
\hline 15. & 130 & 5 & 20 & 0.03 & 7.34 & 3.76 & 1.04 & 0.29 \\
\hline 16. & 175 & 10 & 20 & 6.41 & 11.99 & 5.11 & 4.27 & 9.10 \\
\hline 17. & 220 & 10 & 30 & 14.33 & 0.35 & 0.11 & 0.26 & 68.58 \\
\hline
\end{tabular}

As presented in Table 3, 5-HMF was detected in almost all samples except in those obtained at lower temperatures $\left(130^{\circ} \mathrm{C}\right)$. The amount of 5-HMF ranged from $0.00 \mathrm{mg} / \mathrm{g}$ to $14.33 \mathrm{mg} / \mathrm{g}$. The highest concentration was obtained in the sample 17 (temperature $220^{\circ} \mathrm{C}$, time $10 \mathrm{~min}$, solvent-solid ratio $30 \mathrm{~mL} / \mathrm{g}$ ), and the lowest in the samples 8 (temperature $130{ }^{\circ} \mathrm{C}$, time $15 \mathrm{~min}$, solvent-solid ratio $20 \mathrm{~mL} / \mathrm{g}$ ) and 9 (temperature $130{ }^{\circ} \mathrm{C}$, time $10 \mathrm{~min}$, solvent-solid ratio $10 \mathrm{~mL} / \mathrm{g}$ ). Since it is a compound formed through Maillard and/or caramelization reactions, it can be found in most of the thermal processing of food, especially in carbohydrate-rich foods [35]. In the previous studies of the extractions of citrus, especially mandarin peel [22,36], there is no data presented on 5-HMF in SWE samples to compare the results, but the extracts of the lemon peel showed an increase in the amount of 5-HMF with increasing temperature and extraction time. The highest amount of 5-HMF $(231.21 \pm 3.14 \mathrm{mg} / \mathrm{L})$ was found in lemon peel extract at $180^{\circ} \mathrm{C}$ and $45 \mathrm{~min} .5-\mathrm{HMF}$ in lemon peel extract was determined at $0.64 \mathrm{mg} / \mathrm{L}$ at $140{ }^{\circ} \mathrm{C}$ during SWE but its content in lemon peel extracts increased 20.8 times with the rise of temperature from $140{ }^{\circ} \mathrm{C}$ to $160{ }^{\circ} \mathrm{C}$ for $15 \mathrm{~min}$ during SWE. The temperature of $180^{\circ} \mathrm{C}$ has been shown to be the critical temperature for 5-HMF formation in lemon peel extraction, which can be explained by the decomposition of hemicellulose comprised of different sugar units, among which lemon peel consists of $8.09 \%$ dry weight. Also, the increase in 5-HMF with increasing temperature can be explained by the decomposition of the cell wall at high temperatures and with high lignin content $(7.56 \%)$ of lemon peel [37].

Hesperidin and narirutin were the most abundant flavanones present in the extracts. The concentration of hesperidin detected in the extracts ranged from $0.16 \mathrm{mg} / \mathrm{g}$ to $15.07 \mathrm{mg} / \mathrm{g}$. Furthermore, the lowest concentration was observed in the sample 14 (temperature $220^{\circ} \mathrm{C}$, time $15 \mathrm{~min}$, solvent-solid ratio $20 \mathrm{~mL} / \mathrm{g}$ ), and the highest in the sample 10 (temperature $175^{\circ} \mathrm{C}$, time $5 \mathrm{~min}$, solvent-solid ratio $30 \mathrm{~mL} / \mathrm{g}$ ). The concentration of hesperidin is significantly higher in the extracts obtained at $130^{\circ} \mathrm{C}$ and $175^{\circ} \mathrm{C}$ than at applied higher limit temperature of $220^{\circ} \mathrm{C}$. The concentration of narirutin in the extracts ranged from $0.03 \mathrm{mg} / \mathrm{g}$ to $5.11 \mathrm{mg} / \mathrm{g}$. The lowest concentration was observed in sample 7 (temperature $220^{\circ} \mathrm{C}$, time $10 \mathrm{~min}$, solvent-solid ratio $10 \mathrm{~mL} / \mathrm{g}$ ), and the highest concentration in sample 16 (temperature $175^{\circ} \mathrm{C}$, time $10 \mathrm{~min}$, solvent-solid ratio $20 \mathrm{~mL} / \mathrm{g}$ ). Comparing the results with the literature, it can be seen how other authors have done similar extractions and analyzes. Cheigh et al. [36] recorded the highest yield of hesperidin $(73.5 \pm 0.5 \mathrm{mg} / \mathrm{g}$ of the plant) and narirutin $\left(11.7 \pm 0.8 \mathrm{mg} / \mathrm{g}\right.$ of plant) at the extraction temperature of $160{ }^{\circ} \mathrm{C}$ and solid-liquid ratio of $34 \mathrm{~mL} / \mathrm{g}$ of mandarin peel. Bioactive flavonoids from Citrus unshiu peel were extracted using subcritical water in a semi-continuous mode. With this method 
of extraction, the extraction temperature and flow rate are optimized as the most important parameters. Therefore, the highest yield of hesperidin $(44.62 \mathrm{mg} / \mathrm{g}$ of dry sample) was achieved at $160{ }^{\circ} \mathrm{C}$ and $2.25 \mathrm{~mL} / \mathrm{min}$ during $15 \mathrm{~min}$, and narirutin $(8.00 \mathrm{mg} / \mathrm{g})$ at $150{ }^{\circ} \mathrm{C}$ and $2 \mathrm{~mL} / \mathrm{min}$ during $15 \mathrm{~min}$. Under extraction conditions of $175^{\circ} \mathrm{C}$, for $15 \mathrm{~min}$ and a flow rate of $1.5 \mathrm{~mL} / \mathrm{min}$, the yields of hesperidin and narirutin of $34.75 \mathrm{mg} / \mathrm{g}$ from the dry sample and $6.60 \mathrm{mg} / \mathrm{g}$ were achieved respectively [38]. In another study, the efficiency of hesperidin and narirutin extraction from Citrus unshiu peel using SWE with the extraction temperatures from $110{ }^{\circ} \mathrm{C}$ to $190{ }^{\circ} \mathrm{C}$ and the extraction times from $3 \mathrm{~min}$ to $15 \mathrm{~min}$ were examined. The best yield of hesperidin $(38.45 \mathrm{mg} / \mathrm{g}$ dry peel $)$ was achieved at $150{ }^{\circ} \mathrm{C}$ and $15 \mathrm{~min}$, and for narirutin $(6.56 \mathrm{mg} / \mathrm{g}$ dry peel $)$ it was achieved at $190^{\circ} \mathrm{C}$ and $5 \mathrm{~min}$. The extraction efficiency was improved by a combination of a pulsed electric field (PEF) and SWE where the concentration of hesperidin was $46.96 \pm 3.37 \mathrm{mg} / \mathrm{g}$ peel and narirutin $8.76 \pm 0.83 \mathrm{mg} / \mathrm{g}$ peel [24].

The amount of rutin detected in the extracts was in the range of $0.18 \mathrm{mg} / \mathrm{g}$ to $4.27 \mathrm{mg} / \mathrm{g}$. The lowest concentration of rutin was detected in sample 14 prepared under extraction conditions of $220^{\circ} \mathrm{C}$, time of $15 \mathrm{~min}$, and with solvent-solid ratio of $20 \mathrm{~mL} / \mathrm{g}$. The highest concentration was detected in sample 16 prepared under extraction conditions of $175^{\circ} \mathrm{C}$, $10 \mathrm{~min}$, and at solvent-solid ratio of $20 \mathrm{~mL} / \mathrm{g}$.

In addition, chlorogenic acid as a dominant phenolic acid in the phytochemical profile of SWE extract of Citrus unshiu Marc. var. Kuno was also detected in several samples. The detected values of chlorogenic acid concentration in the prepared extracts ranged from $0.00 \mathrm{mg} / \mathrm{g}$ to $68.58 \mathrm{mg} / \mathrm{g}$. The lowest concentration of chlorogenic acid was recorded in sample 8 (temperature $130{ }^{\circ} \mathrm{C}$, time of $15 \mathrm{~min}$, solvent-solid ratio $20 \mathrm{~mL} / \mathrm{g}$ ), and the highest for sample 17 (temperature $220^{\circ} \mathrm{C}$, time of $10 \mathrm{~min}$, solvent-solid ratio $30 \mathrm{~mL} / \mathrm{g}$ ). This increase in chlorogenic acid can be explained by the degradation of lignin during subcritical water extraction to form secondary metabolites such as flavonoids (luteolin and apigenin) and phenolic acids (chlorogenic acid and dicaffeoylquinic acids). These components are precursors during lignin biosynthesis [39].

\subsection{Response Surface Analysis and Process Optimization}

In order to optimize the extraction process for obtaining the most abundant bioflavonoids presented in mandarin peels (Citrus unshiu Marc. var. Kuno) by employing SWE technique, it is essential to investigate the effects of the operating parameters (temperature, time and solvent-solid ratio) on the individual response (targeted compound). In this study, SWE has been used for the extraction of polyphenolic compounds from the $\mathrm{SC}-\mathrm{CO}_{2}$ pretreated residue of mandarin peel, while the influence of the operating parameters has been investigated regarding to the three the most abundant polyphenolic components in the samples, more precisely, to hesperidin, narirutin, and rutin, as well as to chlorogenic acid and heterocyclic organic compound 5-HMF. The mathematical modeling and process optimization were performed according to the Box-Behnken experimental design, testing also the influence of three process parameters of temperature $\left(130-220^{\circ} \mathrm{C} ; X_{1}\right)$, time (5-15 min; $\left.X_{2}\right)$ and solvent-solid ratio $\left(10-30 \mathrm{~mL} / \mathrm{g} ; X_{3}\right)$ through overall 17 experimental runs (Tables 1 and 3$)$. As expected, the concentration of 5-HMF increases with the increase of extraction temperature, with a maximum concentration detected at $220^{\circ} \mathrm{C}(14.33 \mathrm{mg} / \mathrm{g}$ of peels). By investigating the influence of each individual process parameter on 5-HMF (Figure 1), temperature $\left(X_{1}\right)$ and solvent-solid ratio $\left(X_{3}\right)$ show significant effect on the presence of 5-HMF in the extracts (Table S1). All temperature coefficients and their interactions $\left(X_{1 \times 3}, X_{1}^{2}\right)$ exhibit also significant influence on the presence of 5-HMF, and as it can be seen, the regression model for the response of 5-HMF was significant $(p$-value $<0.05)$ and obtained coefficient of determination was calculated to be $R^{2}=0.9677$. The Equation (2) for the following model was determined as:

$$
\begin{array}{r}
5-H M F=5.95+4.52 X_{1}-0.1786 X_{2}+2.28 X_{3}-1.61 X_{1}^{2}-0.2184 X_{2}^{2} \\
+0.5871 X_{3}^{2}-0.9153 X_{1} X_{2}+2.23 X_{1} X_{3}+0.25 X_{2} X_{3}
\end{array}
$$



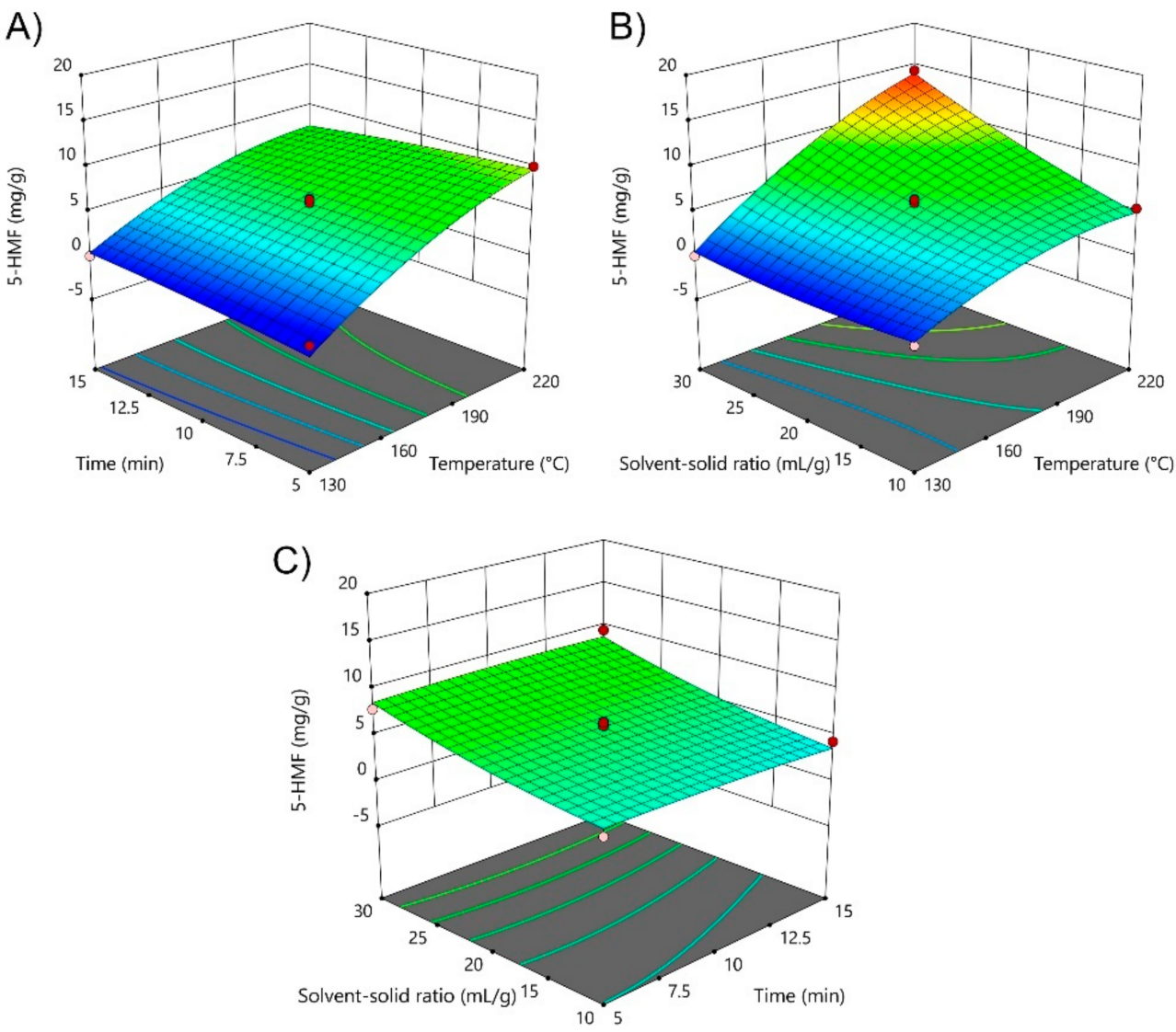

Figure 1. 3D diagrams of the effects of (A) time and temperature; (B) solvent-solid ratio and temperature, and (C) solvent-solid ratio and time on the 5-HMF extraction from mandarin peel (Citrus unshiu Marc. var. Kuno) using SWE technique.

The concentration of 5-HMF at $130{ }^{\circ} \mathrm{C}$ is negligible, reaching its maximum at the highest applied temperature of $220^{\circ} \mathrm{C}$. 5-HMF is in the most cases considered as one of the by-products obtained by thermal degradation of present components in the extracts or by non-enzymatic browning. According to the Lachos-Perez et al. [22], during treatments at high temperatures, the compounds present in plant material could mutually interact to give different by-products, among which 5-HMF is the most commonly detected. However, due to its toxic effect at high concentrations, it is essential to optimize the process in order to reduce its concentration in the extracts, while at the same time to increase the concentration of desirable compounds, such as polyphenolic components. Also, the level of 5-HMF is monitored as an index of nonenzymatic browning and could be used as indicator of quality loss in food products [40].

Hence, the influence of operating extraction parameters was also investigated on the extractability of the three most abundant components in SWE extracts (Figure 2, Figures S3 and S4), hesperidin, narirutin and rutin. 
A)

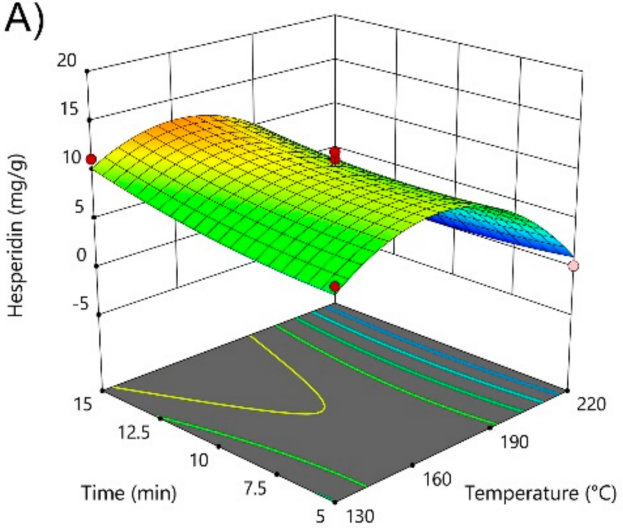

B)

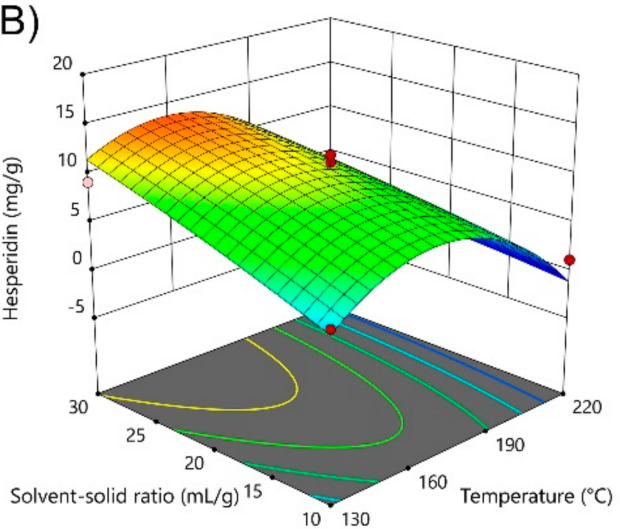

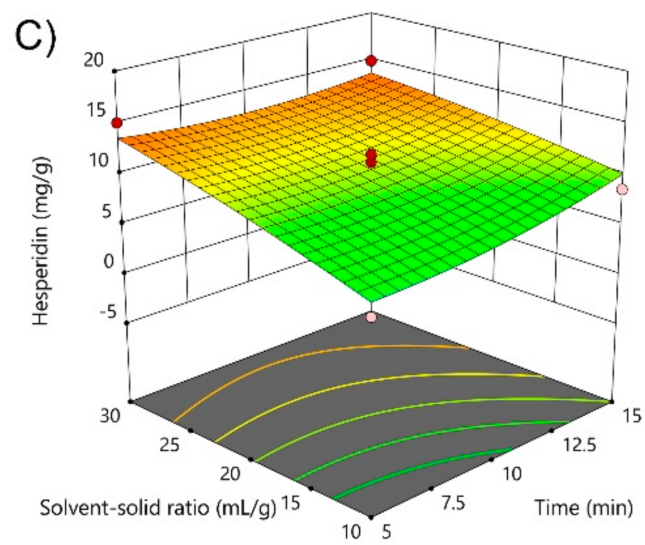

Figure 2. 3D diagrams of the effects of (A) time and temperature; (B) solvent-solid ratio and temperature, and (C) solvent-solid ratio and time on hesperidin extraction from mandarin peel (Citrus unshiu Marc. var. Kuno) using SWE technique.

In the case of the hesperidin and narirutin, the parameters such as temperature $\left(X_{1}\right)$ and solvent-solid ratio $\left(X_{3}\right)$ have significant influence on the extraction of each individual bioflavonoid as it can be noticed from the results of ANOVA analysis summarized in Tables S2 and S3. The temperature $\left(X_{1}\right)$ parameter did not show significant effect, while quadratic coefficient of temperature $\left(X_{1}^{2}\right)$ and solvent-solid ratio $\left(X_{3}\right)$ show significant influence on the extraction of rutin (Table 44 ). The common characteristic for all investigated responses is the significant influence of the solvent-solid ratio $\left(X_{3}\right)$, meaning that as more solvent enters the plant cells, the extraction of phenolic compounds by permeating the cell membrane will be enhanced under higher solvent-solid ratios [41]. Another common characteristic is relatively low stability of flavonoids at the higher temperatures than $>175^{\circ} \mathrm{C}$, indicating the decrease in concentrations by possible thermal degradation of components. Therefore, the maximum contents of individual response are obtained under the highest solvent-solid ratio of approximately $30 \mathrm{~mL} / \mathrm{g}$ and temperatures $\leq 175^{\circ} \mathrm{C}$. An interesting observation has been made regarding the increasing concentration of chlorogenic acid with the increase of temperature (Figure S5). The highest concentration of chlorogenic acid of $68.58 \mathrm{mg} / \mathrm{g}$ of peels has been detected in the experimental run $17\left(220^{\circ} \mathrm{C}, 10 \mathrm{~min}, 30 \mathrm{~mL} / \mathrm{g}\right.$ of peels) of SWE extract of mandarin peel, while significant decrease in concentrations of flavonoids hesperidin, narirutin and rutin has been observed (Figure 3). These findings suggest that chlorogenic acid could be formed as a by-product of thermal degradation of the present components in the extracts at higher temperatures. 


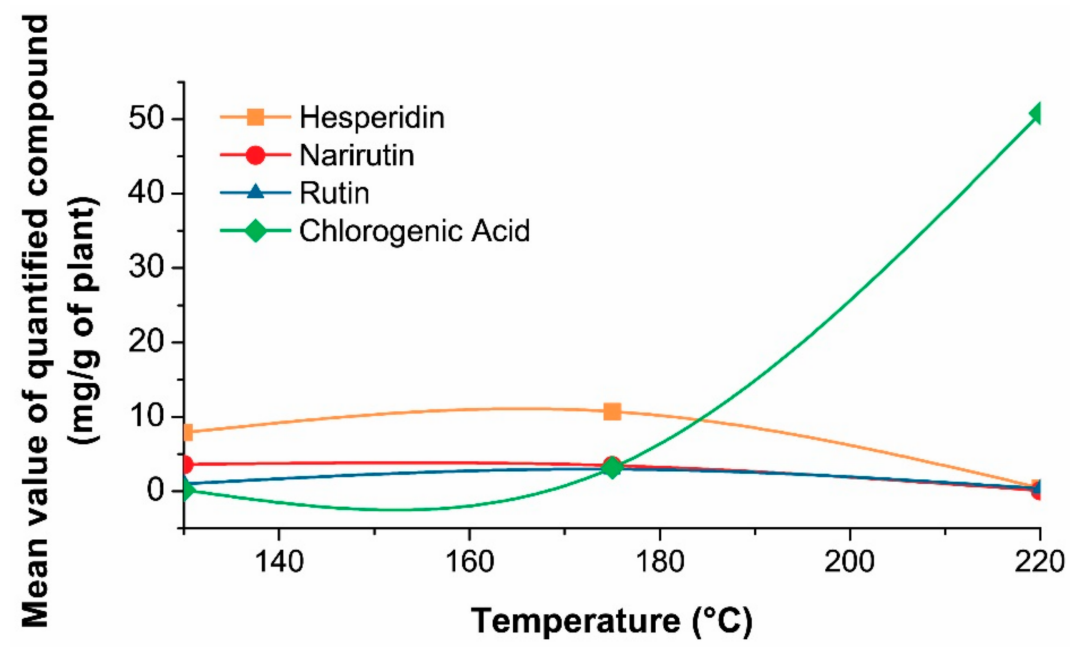

Figure 3. The effect of temperature on the recovery of the three most abundant phenolic compounds and chlorogenic acid in SWE extracts.

The adequacy of the fitted models has been evaluated by the ANOVA analysis shown in Tables S1-S5 (reported in Supplementary Material). As it can be noticed, the models for the extraction of hesperidin, narirutin and rutin are significant $(p$-value $<0.05)$ with obtained coefficient of determination ranging from $R^{2}=0.8487$ to $R^{2}=0.9317$, showing good correlation between fitted and experimental data. The obtained results fit to the quadratic function described by following equation for hesperidin (3), narirutin (4), rutin (5), while chlorogenic acid (6) is fitted to the cubic function as follows:

$$
\begin{gathered}
\text { HESPERIDIN }=10.53-3.7 X_{1}+0.873 X_{2}+2.61 X_{3}-6.58 X_{1}^{2}+0.7849 X_{2}^{2} \\
-0.3627 X_{3}^{2}-0.9838 X_{1} X_{2}-1.58 X_{1} X_{3}-0.8629 X_{2} X_{3} \\
\begin{aligned}
\text { NARIRUTIN }= & 3.84-1.77 X_{1}-0.0268 X_{2}+0.9936 X_{3}-1.57 X_{1}^{2}-0.0753 X_{2}^{2} \\
- & 0.7832 X_{3}^{2}-0.2785 X_{1} X_{2}-0.4381 X_{1} X_{3}+0.1045 X_{2} X_{3} \\
\text { RUTIN }=3.24- & 0.3091 X_{1}-0.1395 X_{2}+0.7244 X_{3}-2.29 X_{1}^{2}-0.3365 X_{2}^{2} \\
- & 0.2277 X_{3}^{2}-0.002 X_{1} X_{2}-0.3326 X_{1} X_{3}+0.123 X_{2} X_{3} \\
\text { CHLOROGENIC } & \text { ACID } \\
= & 3.16+22.37 X_{1}+11.78 X_{1} X_{3}+22.33 X_{1}^{2}+11.88 X_{1}^{2} X_{3} \\
+ & 5.91 X_{1} X_{2}^{2}+1.57 X_{2}^{2}+3.57 X_{2} X_{3}^{2}-1.19 X_{2}^{3}
\end{aligned}
\end{gathered}
$$

One of the main focus of this study is to optimize SWE process by maximizing the content of three most abundant flavonoids in mandarin peel, including also chlorogenic acid, and by minimizing content of undesirable compound 5-HMF using desirability function approach. For obtaining the maximum content of hesperidin and minimum content of 5-HMF by SWE procedure within experimental range, the calculated optimal conditions were $130{ }^{\circ} \mathrm{C}, 14 \mathrm{~min}$, and $29 \mathrm{~mL} / \mathrm{g}$. The optimal conditions for the separation of narirutin $(4.92 \mathrm{mg} / \mathrm{g})$ were $130{ }^{\circ} \mathrm{C}, 14 \mathrm{~min}$, and $27 \mathrm{~mL} / \mathrm{g}$ and $145^{\circ} \mathrm{C}, 8 \mathrm{~min}$, and $29 \mathrm{~mL} / \mathrm{g}$ for obtaining rutin $(3.10 \mathrm{mg} / \mathrm{g})$. As it can be noticed, the optimal conditions values are close to the lower limits of experimental design $\left(130^{\circ} \mathrm{C}\right)$, and are undoubtedly necessary to apply in order to reduce higher concentrations of 5-HMF in the SWE extracts, as 5-HMF is a product of sugar transformation under high temperature conditions. The predicted data obtained with RSM analysis was experimentally verified with satisfactory agreement to the experimental values within deviations of $\pm 10 \%$. The prediction was also verified excluding the condition of minimizing the content of 5-HMF, and results have shown the optimal conditions for maximum content of hesperidin $(15.05 \mathrm{mg} / \mathrm{g})$ as $153{ }^{\circ} \mathrm{C}, 15 \mathrm{~min}$, and $30 \mathrm{~mL} / \mathrm{g}, 140{ }^{\circ} \mathrm{C}, 15 \mathrm{~min}$, and $29 \mathrm{~mL} / \mathrm{g}$ for narirutin $(5.05 \mathrm{mg} / \mathrm{g}), 168^{\circ} \mathrm{C}, 10 \mathrm{~min}$, and $30 \mathrm{~mL} / \mathrm{g}$ for rutin $(3.79 \mathrm{mg} / \mathrm{g})$ and $219^{\circ} \mathrm{C}, 9 \mathrm{~min}$, and $30 \mathrm{~mL} / \mathrm{g}$ for maximum content 
of chlorogenic acid $(68.76 \mathrm{mg} / \mathrm{g})$. The experimental data show good agreement to the predicted data with suitable deviations of $\pm 5 \%$.

\subsection{Antiradical Activity and Total Phenolic Content}

The extracts obtained by SWE were analyzed for antiradical activity and total phenolic content. It is well-known that the antioxidant capacity is enhanced in hydrophilic environment, especially in the presence of the phenolic compounds, and could be reduced in lipophilic environment, such as in SC- $\mathrm{CO}_{2}$ extracts [42]. SWE extracts of mandarin peel exhibited good antiradical activity within the range of $11.14 \pm 5.32 \%$ and $95.28 \pm 0.37 \%$. The highest antiradical activity was detected in the sample obtained at $175^{\circ} \mathrm{C}, 15 \mathrm{~min}$, and at solvent-solid ratio of $30 \mathrm{~mL} / \mathrm{g}$ (run 5). The antiradical activity significantly increases with the increase of temperature from $130{ }^{\circ} \mathrm{C}$ to $175^{\circ} \mathrm{C}$, while decrease in activity is observed with further increase in temperature above $200-220^{\circ} \mathrm{C}$ (Figure $4 \mathrm{~A}$ ).
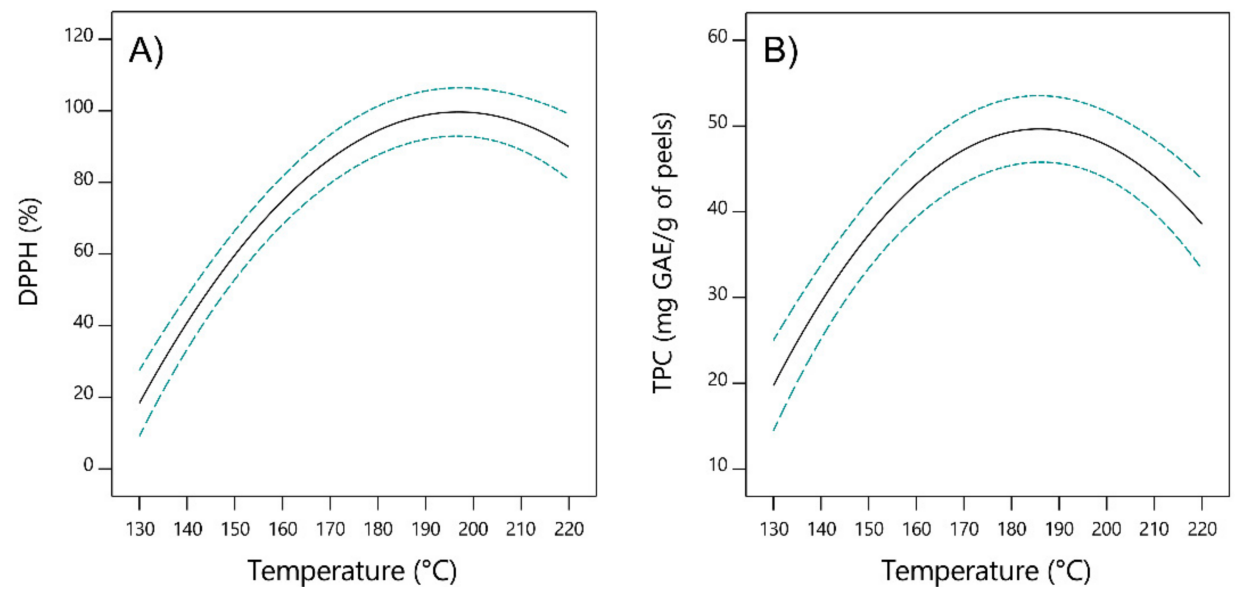

Figure 4. 2D diagram of the effect of the applied extraction temperature on (A) antiradical activity and (B) total phenolic content (TPC).

This clearly indicates that both simple and complex polyphenolic compounds contribute to the antiradical activity, while at the higher temperatures above $160^{\circ} \mathrm{C}$, degradation process of the polyphenolic compounds initiates, mainly of hesperidin and narirutin, which are well known for their good antioxidant capacity [25]. Similar observation was made regarding determination of total phenolic content. At mild conditions of $130{ }^{\circ} \mathrm{C}$, $5 \mathrm{~min}$ and $20 \mathrm{~mL} / \mathrm{g}$, total phenolic content was determined as $15.80 \pm 1.32 \mathrm{mg}$ GAE $/ \mathrm{g}$ of peels, while the highest content of $54.39 \pm 0.63 \mathrm{mg} \mathrm{GAE} / \mathrm{g}$ of peels was detected at the $175^{\circ} \mathrm{C}, 10 \mathrm{~min}, 20 \mathrm{~mL} / \mathrm{g}$ (Figure 4B). The results could be attributed to the greater solubility of phenolic compounds, while at the same time physical characteristics of the contact surface also change (surface tension, viscosity), improving their solubility in the solvent. The correlation between two variables, antiradical activity and total phenolic content, has been also investigated and correlation coefficient was calculated to be $R=0.8823$. These findings indicate that SWE extracts exhibit good antiradical activity with significant content of phenolics, presenting citrus peel extracts as promising plant material for a wide spectrum of applications and potential health benefits.

\section{Conclusions}

This study focuses on the innovative green extraction techniques of the mandarin peel (Citrus unshiu Marc. variety Kuno) to obtain the highly valuable components. Firstly, SC- $\mathrm{CO}_{2}$ extractions at operating pressures of 100 and 300 bar were performed to obtain aromatic components of different chemical complexities, among which limonene was detected as the most dominant volatile compound at both applied pressures, followed by $\alpha$-farnesene, linoleic and hexadecanoic acids. The exhausted residue of mandarin peel remained after $\mathrm{SC}-\mathrm{CO}_{2}$ extraction was further used for extraction of polyphenolic 
compounds using SWE. Based on the obtained results, the most abundant phenolic components in mandarin peel extracts obtained by SWE were hesperidin, narirutin, and rutin. The concentration of these components was dependent on the applied temperature and solvent-solid ratio, with significant decrease observed in extracted content above $160{ }^{\circ} \mathrm{C}$. At these conditions, the higher contents of chlorogenic acid and 5-HMF were detected, which are suggested as by-products of thermal degradation. The extracts obtained at higher temperatures $\leq 175{ }^{\circ} \mathrm{C}$ exhibited good antiradical activity, however the formation of 5-HMF was also observed. Potential limitation of SWE could be attributed to the formation of undesirable components by applying the higher extraction temperatures. Hence, efficient optimization process for obtaining highly valuable and at the same time reducing the content of undesirable components is undoubtedly a study of interest and essential toward possible large-scale applications.

Supplementary Materials: The following are available online at https:/ /www.mdpi.com/article/10 .3390 / foods10051043/s1, Figure S1. HPLC chromatograms; Figure S2. Comparison of UV spectra of standards and unknown peaks; (A) hesperidin, (B) narirutin, (C) rutin, (D) 5-HMF, and (E) chlorogenic acid; Figure S3. 3D diagrams of the effects of process parameters on the formation of narirutin in SWE extracts of mandarin peel (Citrus unshiu var. Kuno); Figure S4. 3D diagrams of the effects of process parameters on the formation of rutin in SWE extracts of mandarin peel (Citrus unshiu var. Кипо); Figure S5. 3D diagram of the effects of process parameters on the formation of chlorogenic acid in SWE extracts of mandarin peel (Citrus unshiu var. Kuno); Table S1. Analysis of variance (ANOVA) of second-order polynomial models for 5-HMF content in the mandarin peels (Citrus unshiu var. Кипо) obtained by SWE technique; Table S2. Analysis of variance (ANOVA) of second-order polynomial models for hesperidin content in the mandarin peels (Citrus unshiu var. Kuno) obtained by SWE technique; Table S3. Analysis of variance (ANOVA) of second-order polynomial models for narirutin content in the mandarin peels (Citrus unshiu var. Kuno) obtained by SWE technique; Table S4. Analysis of variance (ANOVA) of second-order polynomial models for rutin content in the mandarin peels (Citrus unshiu var. Kuno) obtained by SWE technique; Table S5. Analysis of variance (ANOVA) of reduced third-order polynomial models for chlorogenic acid content in the mandarin peels (Citrus unshiu var. Kuno) obtained by SWE technique.

Author Contributions: All the authors discussed and planned the paper; S.Š., M.J., I.J., D.Š. and S.J. drafted the manuscript; I.J. performed analysis of volatile compounds by GC-MS and supplemented and corrected the manuscript draft; M.J. performed HPLC analysis of polyphenols; S.Š., I.Ć. performed the subcritical water extraction experiments; K.A. performed supercritical $\mathrm{CO}_{2}$ extractions; S.Š. and I.Ć. performed antiradical testing and determination of total phenolic content in obtained extracts; S.Š. and S.J. performed optimization using response surface analysis; S.Š., D.Š., I.J. and S.J. reviewed and edited the manuscript; funding acquisition was obtained by S.J. All authors have read and agreed to the published version of the manuscript.

Funding: This research was funded by Croatian Science Foundation under the project UIP-2017-05-9909.

Institutional Review Board Statement: Not applicable.

Informed Consent Statement: Not applicable.

Data Availability Statement: The data presented in this study are available for limited time on request from the corresponding author.

Acknowledgments: This work has been supported by Croatian Science Foundation under the project "Application of innovative techniques of the extraction of bioactive compounds from by-products of plant origin" (UIP-2017-05-9909).

Conflicts of Interest: The authors declare no conflict of interest.

\section{References}

1. Khedkar, R.; Singh, K. Food Industry Waste: A Panacea or Pollution Hazard? In Paradigms in Pollution Prevention, 1st ed.; Jindal, T., Ed.; Springer: Cham, Switzerland, 2018; pp. 35-47. [CrossRef]

2. Zema, D.A.; Calabrò, P.S.; Folino, A.; Tamburino, V.; Zappia, G.; Zimbone, S.M. Valorisation of citrus processing waste: A review. Waste Manag. 2018, 80, 252-273. [CrossRef] [PubMed] 
3. Anticona, M.; Blesa, J.; Frigola, A.; Esteve, M.J. High Biological Value Compounds Extraction from Citrus Waste with NonConventional Methods. Foods 2020, 9, 811. [CrossRef] [PubMed]

4. Ruano, P.; Delgado, L.L.; Picco, S.; Villegas, L.; Tonelli, F.; Merlo, M.E.A.; Rigau, J.; Diaz, D.; Masuelli, M. Extraction and Characterization of Pectins From Peels of Criolla Oranges (Citrus sinensis): Experimental Reviews. In Pectins-Extraction, Purification, Characterization and Applications; Masuelli, M., Ed.; IntechOpen: London, UK, 2020. [CrossRef]

5. Jokić, S.; Molnar, M.; Cikoš, A.; Jakovljević, M.; Šafranko, S.; Jerković, I. Separation of selected bioactive compounds from orange peel using the sequence of supercritical $\mathrm{CO}_{2}$ extraction and ultrasound solvent extraction: Optimization of limonene and hesperidin content. Sep. Sci. Technol. 2019, 55, 2799-2811. [CrossRef]

6. Sawamura, M. Citrus Essential Oils: Flavor and Fragrance, 1st ed.; John Wiley \& Sons, Inc.: Hoboken, NJ, USA, 2010.

7. Mahato, N.; Sharma, K.; Sinha, M.; Baral, E.; Koteswararao, R.; Dhyani, A.; Cho, M.H.; Cho, S. Bio-sorbents, industrially important chemicals and novel materials from citrus processing waste as a sustainable and renewable bioresource: A review. J. Adv. Res. 2020, 23, 61-82. [CrossRef] [PubMed]

8. Jokić, S.; Šafranko, S.; Jakovljević, M.; Cikoš, A.-M.; Kajić, N.; Kolarević, F.; Babić, J.; Molnar, M. Sustainable Green Procedure for Extraction of Hesperidin from Selected Croatian Mandarin Peels. Processes 2019, 7, 469. [CrossRef]

9. Mackenzie, L.; Tyrrell, H.; Thomas, R.; Matharu, A.; Clark, J.; Hurst, G. Valorization of Waste Orange Peel to Produce ShearThinning Gels. J. Chem. Educ. 2019, 96, 3025-3029. [CrossRef]

10. Teixeira, F.; Novello, D. Physico-chemical. nutritional and sensory aspects of the addition of Citrus fruit by-products in gelation products: A systematic review. Res. Soc. Dev. 2020, 9, e180932669. [CrossRef]

11. Vidović, S.; Vladić, J.; Nastić, N.; Jokić, S. Subcritical and Supercritical Extraction in Food By-product and Food Waste Valorization. In Innovative Food Processing Technologies, 1st ed.; Knoerzer, K., Muthukumarappan, K., Eds.; Elsevier: Amsterdam, The Netherlands, 2021; pp. 705-721.

12. Imran, M.; Basharat, S.; Khalid, S.; Aslam, M.; Syed, F.; Jabeen, S.; Kamran, H.; Shahidm, M.Z.; Tufail, T.; Shah, F.-H.; et al. Citrus Peel Polyphenols: Recent Updates and Perspectives. Int. J. Biosci. 2020, 16, 53-70. [CrossRef]

13. Koolaji, N.; Shammugasamy, B.; Schindeler, A.; Dong, Q.; Dehghani, F.; Valtchev, P. Citrus Peel Flavonoids as Potential Cancer Prevention Agents. Curr. Dev. Nutr. 2020, 4, nzaa025. [CrossRef] [PubMed]

14. Liew, S.; Ho, W.; Yeap, S.; Sharifudin, S. Phytochemical composition and in vitro antioxidant activities of Citrus sinensis peel extracts. Peer 2018, 6, e5331. [CrossRef] [PubMed]

15. Tinh, N.T.T.; Sitolo, G.C.; Yamamoto, Y.; Suzuki, T. Citrus limon Peel Powder Reduces Intestinal Barrier Defects and Inflammation in a Colitic Murine Experimental Model. Foods 2021, 10, 240. [CrossRef]

16. Mahato, N.; Sharma, K.; Koteswararao, R.; Sinha, M.; Baral, E.; Cho, M. Citrus essential oils: Extraction, authentication and application in food preservation. Crit. Rev. Food Sci. Nutr. 2017, 59, 611-625. [CrossRef]

17. Mahmoud, A.; Hernández Bautista, R.; Sandhu, M.; Hussein, O. Beneficial Effects of Citrus Flavonoids on Cardiovascular and Metabolic Health. Oxid. Med. Cell. Longev. 2019, 2019, 1-19. [CrossRef]

18. Parhiz, H.; Roohbakhsh, A.; Soltani, F.; Rezaee, R.; Iranshahi, M. Antioxidant and Anti-Inflammatory Properties of the Citrus Flavonoids Hesperidin and Hesperetin: An Updated Review of their Molecular Mechanisms and Experimental Models. Phytother. Res. 2014, 29, 323-331. [CrossRef]

19. Tejada, S.; Pinya, S.; Martorell, M.; Capó, X.; Tur, J.; Pons, A.; Sureda, A. Potential Anti-inflammatory Effects of Hesperidin from the Genus Citrus. Curr. Med. Chem. 2019, 25, 4929-4945. [CrossRef]

20. Cho, J. Antioxidant and neuroprotective effects of hesperidin and its aglycone hesperetin. Arch. Pharm. Res. 2006, 29, 699. [CrossRef]

21. Aggarwal, V.; Tuli, H.; Thakral, F.; Singhal, P.; Aggarwal, D.; Srivastava, S.; Pandey, A.; Sak, K.; Varol, M.; Khan, M.; et al. Molecular mechanisms of action of hesperidin in cancer: Recent trends and advancements. Exp. Biol. Med. 2020, 245, 486-497. [CrossRef]

22. Lachos-Perez, D.; Baseggio, A.; Mayanga-Torres, P.; Maróstica, M.; Rostagno, M.; Martínez, J.; Forster-Carneiro, T. Subcritical water extraction of flavanones from defatted orange peel. J. Supercrit. Fluids. 2018, 138, 7-16. [CrossRef]

23. Kim, D.-S.; Lim, S.-B. Semi-Continuous Subcritical Water Extraction of Flavonoids from Citrus unshiu Peel: Their Antioxidant and Enzyme Inhibitory Activities. Antioxidants 2020, 9, 360. [CrossRef]

24. Hwang, H.J.; Kim, H.J.; Ko, M.J.; Chung, M.-S. Recovery of hesperidin and narirutin from waste Citrus unshiu peel using subcritical water extraction aided by pulsed electric field treatment. Food Sci. Biotechnol. 2021, 30, 217-226. [CrossRef]

25. Ko, M.; Kwon, H.; Chung, M. Pilot-scale subcritical water extraction of flavonoids from satsuma mandarin (Citrus unshiu Markovich) peel. Innov. Food Sci. Emerg. Technol. 2016, 38, 175-181. [CrossRef]

26. Jokić, S.; Horvat, G.; Aladić, K. Design of SFE System Using a Holistic Approach—Problems and Challenges. In Supercritical Fluid Extraction: Technology. Applications and Limitations; Lindy, J., Ed.; Nova Science Publishers Inc.: New York, NY, USA, 2015; pp. 95-122.

27. Jerković, I.; Družić, J.; Marijanović, Z.; Gugić, M.; Jokić, S.; Roje, M. GC-FID/MS Profiling of Supercritical CO 2 Extracts of Peels from Citrus aurantium, C. sinensis cv. Washington navel, C. sinensis cv. Tarocco and C. sinensis cv. Doppio Sanguigno from Dubrovnik Area (Croatia). Nat. Prod. Commun. 2015, 10, 1315-1318. [CrossRef]

28. Jokić, S.; Aladić, K.; Šubarić, D. Subcritical water extraction laboratory plant design and application. Annu. Croat. Acad. Eng. 2018, 21, 247-258. Available online: https://hrcak.srce.hr/216152 (accessed on 19 March 2021). 
29. Molnar, M.; Jerković, I.; Suknović, D.; Bilić Rajs, B.; Aladić, K.; Šubarić, D.; Jokić, S. Screening of Six Medicinal Plant Extracts Obtained by Two Conventional Methods and Supercritical $\mathrm{CO}_{2}$ Extraction Targeted on Coumarin Content, 2,2-Diphenyl-1picrylhydrazyl Radical Scavenging Capacity and Total Phenols Content. Molecules 2017, 22, 348. [CrossRef]

30. Baş, D.; Boyac1, I. Modeling and optimization I: Usability of response surface methodology. J. Food Eng. 2007, 78, 836-845. [CrossRef]

31. Jokić, S.; Bijuk, M.; Aladić, K.; Bilić, M.; Molnar, M. Optimisation of supercritical $\mathrm{CO}_{2}$ extraction of grape seed oil using response surface methodology. Int. J. Food Sci. Technol. 2015, 51, 403-410. [CrossRef]

32. Jakovljević, M.; Jokić, S.; Molnar, M.; Jašić, M.; Babić, J.; Jukić, H.; Banjari, I. Bioactive Profile of Various Salvia officinalis L. Preparations. Plants 2019, 8, 55. [CrossRef]

33. Cvetanović, A.; Švarc-Gajić, J.; Gašić, U.; Tešić, Ž.; Zengin, G.; Zeković, Z.; Đurović, S. Isolation of apigenin from subcritical water extracts: Optimization of the process. J. Supercrit. Fluids 2017, 120, 32-42. [CrossRef]

34. Lopresto, C.G.; Meluso, A.; Di Sanzo, G.; Chakraborty, S.; Calabro, V. Process-intensified waste valorization and environmentally friendly D-limonene extraction. Euro-Mediterr. J. Environ. Integr. 2019, 4, 31. [CrossRef]

35. Teixido, E.; Santos, F.J.; Puignou, L.; Galceran, M.T. Analysis of 5-hydroxymethylfurfural in foods by gas chromatography-mass spectrometry. J. Chromatogr. A 2006, 1135, 85-90. [CrossRef] [PubMed]

36. Cheigh, C.; Chung, E.; Chung, M. Enhanced extraction of flavanones hesperidin and narirutin from Citrus unshiu peel using subcritical water. J. Food Eng. 2012, 110, 472-477. [CrossRef]

37. Marín, F.R.; Soler-Rivas, C.; Benavente-García, O.; Castillo, J.; Pérez-Alvarez, J.A. By-products from different citrus processes as a source of customized functional fibres. Food Chem. 2007, 100, 736-741. [CrossRef]

38. Kim, D.S.; Lim, S.B. Extraction of flavanones from immature Citrus unshiu pomace: Process optimization and antioxidant evaluation. Sci. Rep. 2020, 10, 19950. [CrossRef]

39. Kanmaz, E.Ö. 5-Hydroxymethylfurfural (HMF) formation during subcritical water extraction. Food Sci. Biotechnol. 2018, 27, 981-986. [CrossRef]

40. Wijngaard, H.; Brunton, N. The Optimization of Extraction of Antioxidants from Apple Pomace by Pressurized Liquids. J. Agric. Food Chem. 2009, 57, 10625-10631. [CrossRef]

41. Jokić, S.; Gagić, T.; Knez, Ž.; Banožić, M.; Škerget, M. Separation of active compounds from tobacco waste using subcritical water extraction. J. Supercrit. Fluids 2019, 153, 104593. [CrossRef]

42. Khan, M.; Zill, E.H.; Dangles, O. A comprehensive review on flavanones, the major citrus polyphenols. J. Food Compost. Anal. 2014, 33, 85-104. [CrossRef] 